\title{
Study of Tunnel wall set effect on the FDS simulation results
}

\author{
Yang.Guo ${ }^{1 \text { a }}$, Shu.Hui. Xu, Qingru Hao \\ ${ }^{1}$ The research centre of comprehensive and effective energy engineering \\ axinghan3424@sina.com
}

Keywords: tunnel physical experiment; The FDS. Wall Settings; The temperature distribution.

Abstract: Recently there exist majority of simplified simulation situation of tunnel wall.To analyse how the simplified situation influences the result of simulation, this paper study conducted analysis of a certain range of temperature distribution within tunnel through the tunnel physical experiment. At the same time, using FDS simulation establishes adiabatic wall and the physical model of a wall. The experiment compared the influence on the temperature distribution and gas diffusion of different sets of the wall .

\section{Introduction}

With the rapid development of our social economy, road and rail traffic mileage get rapid ascension, a large number of tunnels are putting into operation, the tunnel fire caused great influence to traffic and personnel safety. The characteristics of tunnel fire, such as spreading fast, not easy to control, accompanied by a lot of smoke and heat caused difficulties for rescuers to save and put off the tunnel fire. Therefore, to understand the rules of tunnel fire smoke movement for fire fighting and rescue operations is of great significance. Mainly two methods to study fire smoke movement law are computer simulation and experiment.

Recent research on tunnel fire simulation calculation at home and abroad is generally to simplify the processing surface, such as seting into adiabatic wall, firstly it is a simplified heat transfer to obtain a conservative field analysis, secondly it saves the computing resources. But there exist a certain differences between simplified situation with the actual situation, in this paper, to know the difference, the experiment and the FDS simulation show us the result by changing the setting of tunnel wall.

\section{Experimental situation}

Test was in Meteorological Environmental Laboratory located in Dadushe town , tongzhou district of Beijing . This lab is a vaulted tunnel shape, $250 \mathrm{~m}$ long, $8.7 \mathrm{~m}$ wide, vault $8 \mathrm{~m}$ tall. Tunnel wall materials is for polystyrene sandwich plastic steel (thermal deformation temperature is $70 \sim 80{ }^{\circ} \mathrm{C}$ ). Inside the tunnel side there is a row control room, $2.5 \mathrm{~m}$ wide, $3.1 \mathrm{~m}$ high. Fig. 1 is tunnel contour and the internal images.

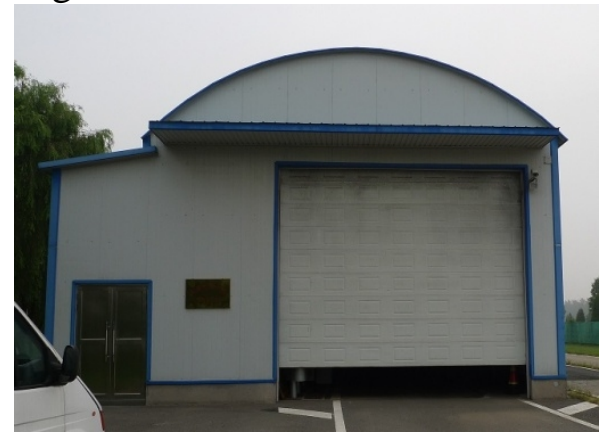

a) External image of the test tunnel

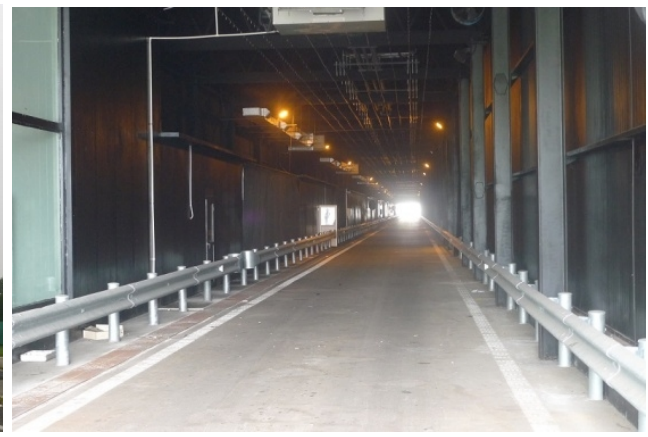

b) Internal image of the test tunnel

Fig. 1 test tunnel

the tunnel fire setting

Fire Settings references to 《GAT999-2012 hot smoke experimental law $\rangle^{1}$. Each burning plate size for A1 $=0.84 \mathrm{~m}$ by $0.60 \mathrm{~m}$. Fuel with $95 \%$ ethanol (industrial alcohol). Due to the temperature of the test requirements in the process of ceiling does not exceed $70{ }^{\circ} \mathrm{C}$, release rate is small, $700 \mathrm{kw}$. Fire 
equipment diagram is shown in figure 2. Field test of ignition device is shown in figure 3 . Test device of fuel additives and the corresponding fire heat release rate are shown in table 1 . In the $60 \mathrm{~m}$ away from the entrance of the tunnel fire decoration.
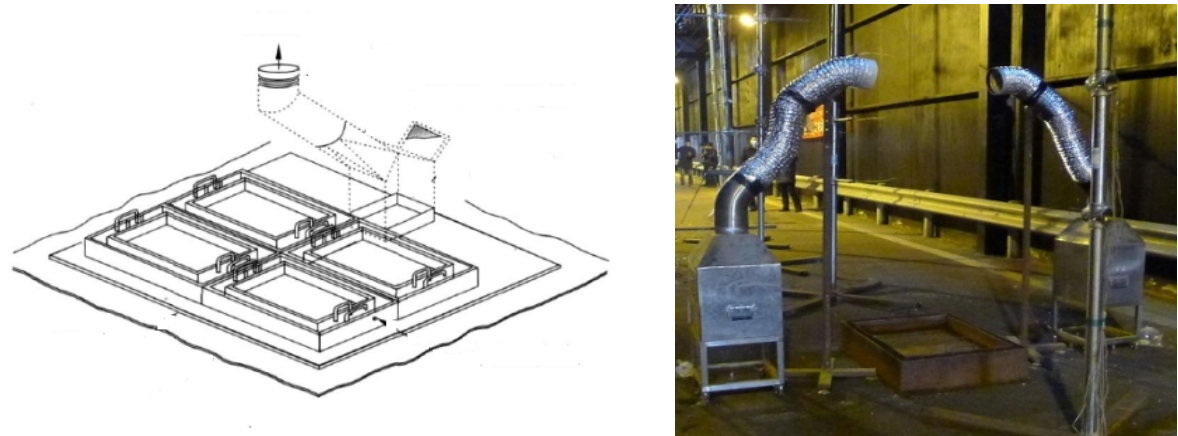

Figure 2 fire device schematic diagram Figure 3 fire equipment in the experiments Table 1 trials and fire heat release rate for the amount of fuel

\begin{tabular}{lllll}
\hline $\begin{array}{l}\text { Burning disk } \\
\text { size }\end{array}$ & $\begin{array}{l}\text { Number of } \\
\text { Burning disk }\end{array}$ & Fuel fill $(\mathrm{L})$ & $\begin{array}{l}\text { Heat release } \\
\text { rate per unit } \\
\text { area }(\mathrm{KW} / \mathrm{m} 2)\end{array}$ & $\begin{array}{l}\text { Total heat } \\
\text { release rate } \\
(\mathrm{kW})\end{array}$ \\
\hline $0.84 \mathrm{~m} \times 0.60 \mathrm{~m}$ & 2 & $2 \times 15.0$ & 696 & 700 \\
\hline
\end{tabular}

experimental measurement system temperature measurement system

In this experiment, $\mathrm{K}$ type thermocouple with $3 \mathrm{~mm}$ probe diameter, can measure the temperature range of $0 \sim 800{ }^{\circ} \mathrm{C}$, the precision is $0.1{ }^{\circ} \mathrm{C}$. $\mathrm{K}$ type thermocouples used in the experiment are shown in figure 2-3.
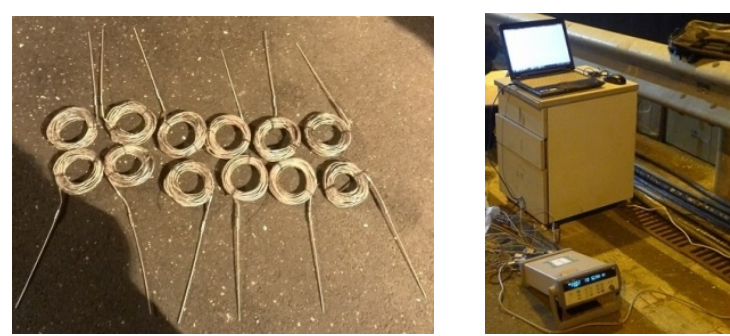

Figure 4 images of $\mathrm{K}$ type thermocouple used in the experiments and agilent temperature collection device connected to the computer

The thermocouple decorated in the corresponding section of the vertical thermocouple tree, is to measure the vertical distribution in the flue gas temperature. As the test fires release rate is small, the temperature scope is limited, so the selection of four temperature section is close to from the fire source. The relative position of the thermocouple tree as shown in figure 5.

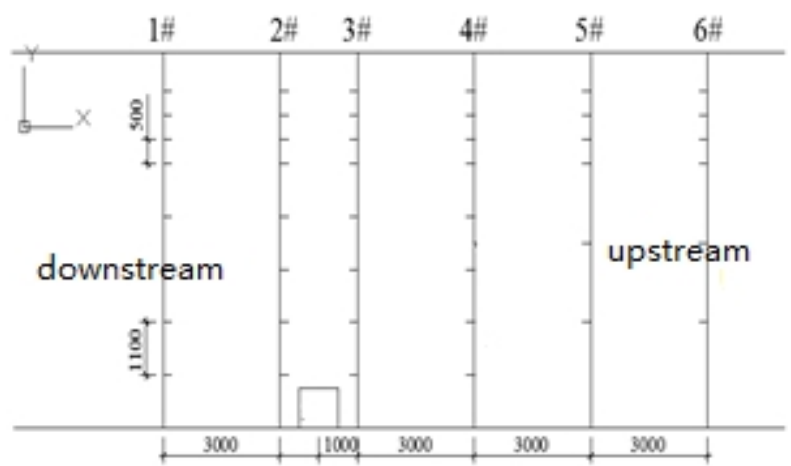

Figure 5 thermocouple tree sketch map

Upstream from the fire 1, 2 \#, and Downstream 3, 4 \#, thermocouple tree decorate 8 thermocouples respectively, downstream \# 5, 6, the thermocouple tree decorated six thermocouple respectively, dredge the close distance. Thermocouple decorate $1 \sim 4$ \# the tree height are $1.1 \mathrm{~m}, 1.1 \mathrm{~m}, 3.3 \mathrm{~m}, 4.4$ 
$\mathrm{m}, 5.5 \mathrm{~m}, 6.0 \mathrm{~m}, 6.5 \mathrm{~m}, 7.0 \mathrm{~m} .5 \sim 6$ \# tree thermocouple decorate a height of $2.2 \mathrm{~m}, 3.85 \mathrm{~m}, 5.5 \mathrm{~m}, 6.0$ $\mathrm{m}, 6.5 \mathrm{~m}, 7.0 \mathrm{~m}$.

velocity measurement system

This experiment adopts four speed measuring probe and wild KA12 four channels anemometer, measuring wind speed,and layout in \# 5 thermocouple tree, measuring the average speed of 5 \# section, which showed in figure 6 .

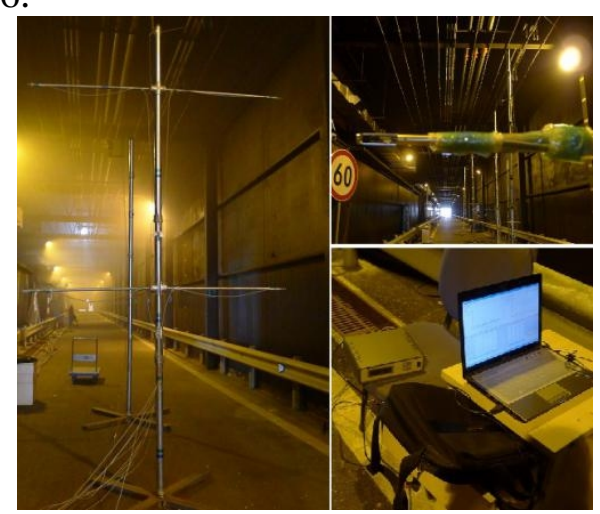

Figure 6 speed sensor arrangement

\section{the simulation process}

FDS is developed by NIST field simulation program in the United States, its working principle is to use numerical simulation method, reflect the detail fire phenomenon, and simulate different parameter, such as temperature, pressure, gas distribution under the fire accident. 2

fire design and the determination of boundary conditions

Fire source is in fire downwind, with distance of $60 \mathrm{~m}$ from tunnel entrance, it consists of two $0.8 \mathrm{~m}$, $0.6 \mathrm{~m}$ wide long rectangular burning plate, after a certain simplification, fire growth curve is in the form of square fire, heat release rate is $696 \mathrm{kw} / \mathrm{m} 2$, fire growth rate is 0.18 ,. Air inlet velocity is 0.56 $\mathrm{m} / \mathrm{s}$, same with the experimental conditions. Outdoor temperature is $15^{\circ} \mathrm{C}$, air outlet is for the open boundary conditions.

Tunnel ground, adopted adiabatic boundary condition, actual experimental tunnel roof and wall is steel. the followings are two situations:

A adiabatic wall, wall thickness is $0 \mathrm{~mm}$

B two steel walls among which is sandwich wall, steel thickness of two sides is $1 \mathrm{~mm}$, the thickness of the terms sandwich wall is $8 \mathrm{~mm}$.

the grid set and time set

Through calculation, close to the fire area on a fine grid, the grid size is $0.17 \mathrm{~m}$, the far field is relatively coarse mesh, the grid size is $0.37 \mathrm{~m}$. Because the fire developing stage is important for escaping, the simulation of this paper mainly focuses on fire development stage. The simulation time is set to $200 \mathrm{s.}^{2}$
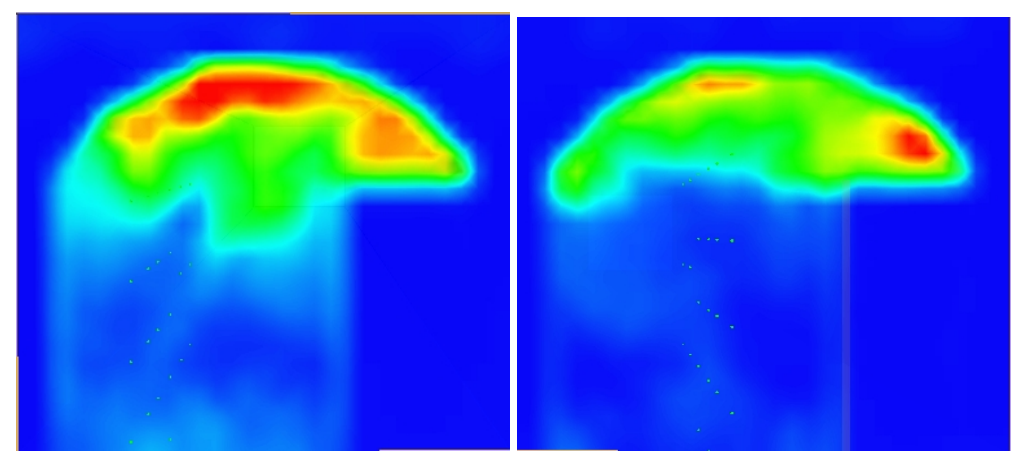

Figure $7 \mathrm{~T}=100 \mathrm{~s}$, the temperature distribution of two kinds of working condition of $70 \mathrm{~m}$ in cross section 


\section{The simulation results analysis}

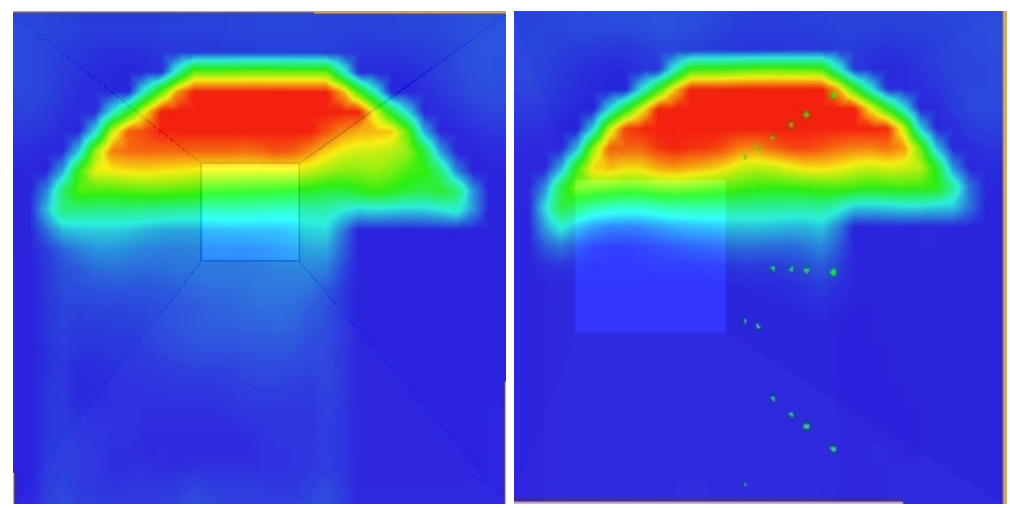

Figure $8 \mathrm{~T}=100$ s, the temperature distribution of two kinds of working condition of $100 \mathrm{~m}$ in cross section

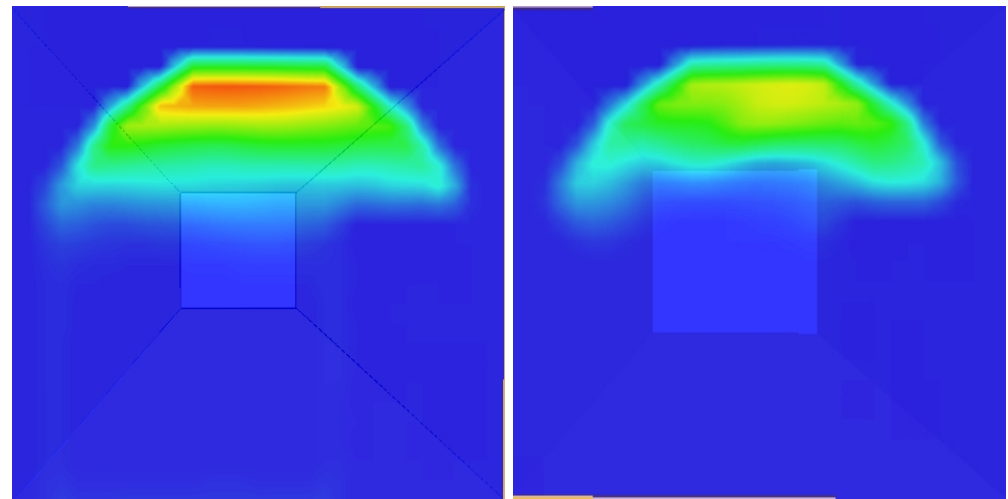

Figure $9 \mathrm{~T}=100 \mathrm{~s}$, the temperature distribution of two kinds of working condition of $100 \mathrm{~m}$ in cross section

When two kinds of wall boundary conditions are not the same,the temperature distribution is almost identical and there is apparent thermal stratification effect which is the more distance to the fire source, the lower temperature is.But the temperature value is different, while there is heat insulation working condition and most smoke is in the developing phase, the temperature of hot layer in three different cross section is all higher than 'steel' working condition.Now,there are six different thermocouple temperature values which are the average temperature in 200 seconds at the different height to state this result.
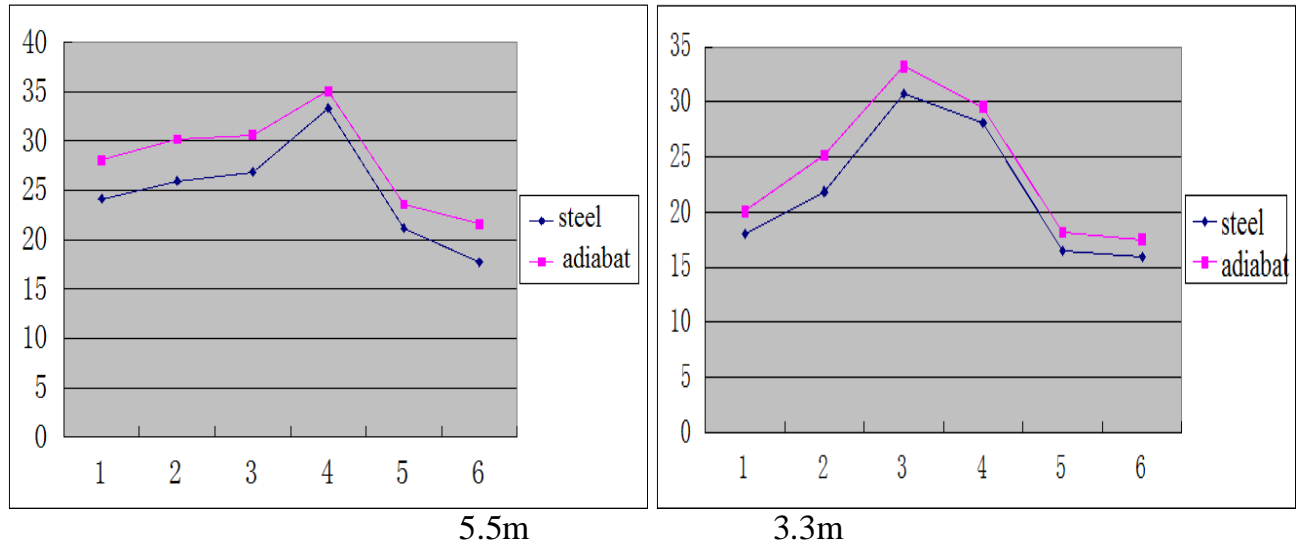

Figure 10 the temperature distribution of different thermocouple tress

They have the same temperature variation trend but the temperature of the heat isolation working condition is higher $3-5^{\circ} \mathrm{C}$ than the color plate working condition and they have 10 percentage difference.In the heat isolation working condition, high temperature in the tunnel has the only heat exchange with inlet cool air, while in the steel working condition, high temperature in the tunnel is lower than heat isolation wall working condition because of increasing heat exchange with the wall.Considering the temperature variation tendency and temperature distribution in space, the temperature of the heat isolation working condition and the color plate working condition meets 
physical truth.Because of the simplification of fire source, the temperature difference by the fire height is not considered, so there is the temperature difference between two thermocouple tree close to the fire source.Now considering the thermocouple trees' average temperature which is away from fire the fire source in 20 minutes, there are contrast results with experiment value between two working condition. ${ }^{3}$

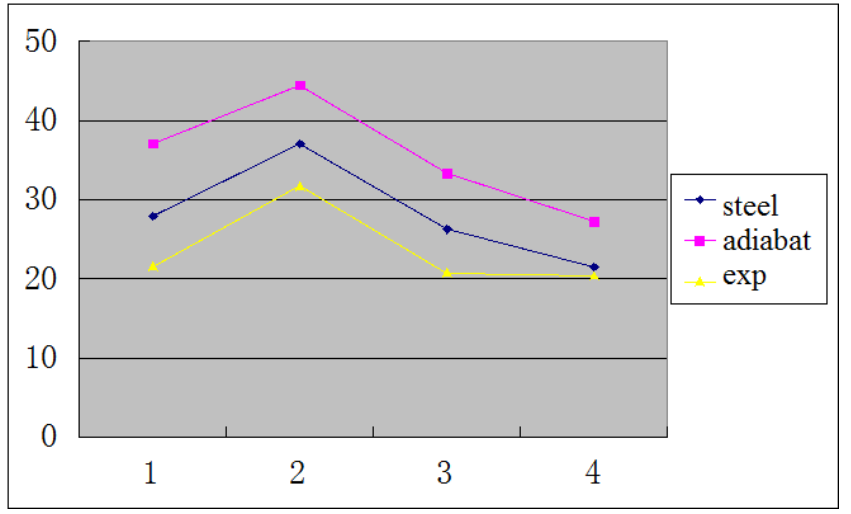

Figure 11 the temperature distribution of two work conditions and experiment

On the current fire source power, the contagious process of smoke is the same.Actually the temperature of the heat isolation working condition which is high and makes the flotage more bigger leads to the rate of descent of smoke slowly,so the simulated result is different form physical truth.The possible reason is that the fire source power is small, and the rate of smoke to the wall is not clear.Below this pictures, they are contagious process of 'steel' working condition, the same as the heat isolation working condition。The height of smoke distribute are higher than the experiment.

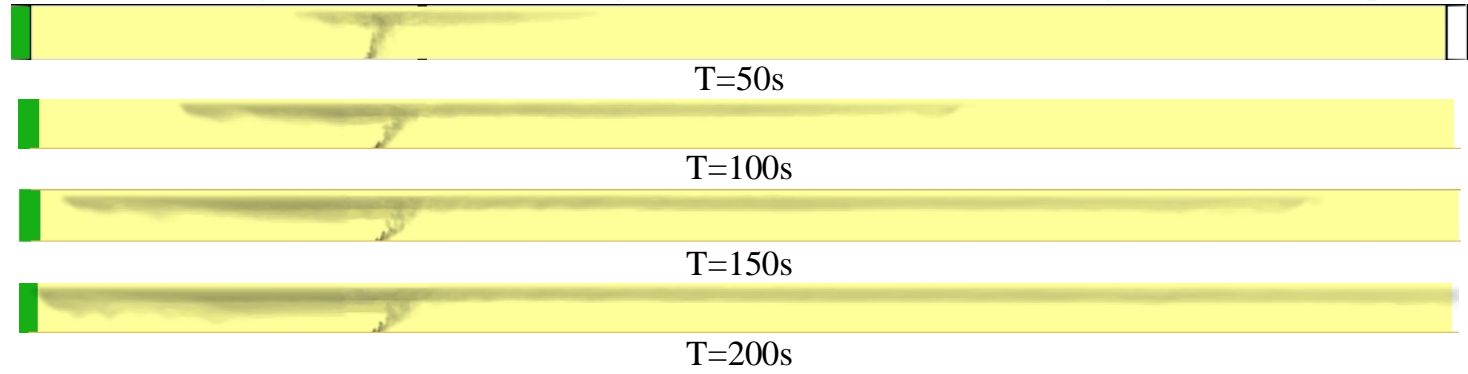

Figure 12 the height of smoke of simulation

Table 2 Smoke settlement time record

\begin{tabular}{ccccc}
\hline Heightm & \multicolumn{4}{c}{ Time } \\
\cline { 2 - 5 } & $40 \mathrm{~m}$ & $80 \mathrm{~m}$ & $115 \mathrm{~m}$ & $160 \mathrm{~m}$ \\
\hline 5.5 & $00: 03: 41: 00$ & $00: 04: 17: 63$ & $00: 04: 21: 00$ & $00: 06: 57: 00$ \\
4.5 & $00: 05: 02: 00$ & $00: 05: 18: 26$ & $00: 06: 09: 00$ & $00: 08: 08: 00$ \\
4.0 & $00: 05: 51: 00$ & $00: 05: 43: 63$ & $00: 06: 57: 00$ & $00: 09: 05: 00$ \\
3.5 & $00: 06: 10: 00$ & $00: 06: 08: 17$ & $00: 07: 42: 00$ & $00: 09: 51: 00$ \\
3.0 & $00: 07: 01: 00$ & $00: 06: 46: 73$ & - & $00: 10: 29: 00$ \\
2.5 & $00: 07: 44: 00$ & $00: 07: 10: 35$ & $00: 08: 12: 00$ & $00: 11: 00: 00$ \\
2.0 & $00: 08: 12: 00$ & $00: 08: 31: 56$ & $00: 09: 30: 00$ & $00: 12: 34: 00$ \\
1.5 & $00: 08: 31: 00$ & $00: 08: 49: 56$ & $00: 10: 47: 00$ & $00: 13: 29: 00$ \\
\hline
\end{tabular}

\section{conclusion}

Setting the FDS wall material could influence the temperature in the tunnel, but the temperature distribution not.The influence of temperature depends on the material temperature 、 heat conductivity coefficient 、 absorptivity and boundary setting, it can have a ten percent of degree of influence.

When the fire source power is small, there is little effects to the change of wall condition to the process of the diffusion of fire smoke. We need more study to know how high the fire source power is could cause 
sufficient impact.

In possible calculating condition, we should set the real wall as possible.

\section{Acknowledgement}

Project supported by Energy and Power Engineering Specialty Construction and Beijing Municipality Key Lab of Heating, Gas Supply, Ventilating and Air Conditioning Engineering.

\section{REFERENCES}

1、GAT999-2012 hot smoke experimental law

2、 Chow,W.K. Simulation of Tunnel Fires Using a Zone Model. Tunnelling and Underground Space Technology[J], 1996(11), 221-236.

3、W.K.Chow. Application of computational fluid dynamics in building services engineering.Building and Environment[J]. 1996: 425-436. 